\title{
Expression of TAG1/APP signaling pathway in the proliferation and differentiation of glioma stem cells
}

\author{
YUN-BO ZHEN, XIAO-FENG CHEN, TAO YAN and SHI-GUANG ZHAO \\ The First Affiliated Hospital of Harbin Medical University, Harbin, Heilongjiang 150001, P.R. China
}

Received May 17, 2016; Accepted May 31, 2017

DOI: $10.3892 / \mathrm{ol} .2017 .6381$

\begin{abstract}
The aim of the present study was to examine the role of the expression of transient axonal glycoprotein-1 (TAG1)/precursor protein (APP) signaling pathway in the proliferation and differentiation of glioma stem cells. A glioma cell line (U373) was used as well as fluorescence quantitative PCR, western blot analysis, and enzyme-linked immunosorbent assay (ELISA), to examine the role of the expression of TAG1/APP signaling pathway in the proliferation and differentiation of glioma stem cells after five generations of in vitro culture. The results showed that compared to the normal glioma cells, the expression of TAG1 and APP was significantly increased in the proliferation of glioma stem cells. The results of ELISA and western blot analysis also confirmed a significant elevation in the protein expression of TAG1 in glioma stem cells compared to normal human glioma cells. When glioma stem cells were cultured in differentiation medium, as revealed by RT-PCR, the expression of TAG1 and APP in glioma stem cells initially increased and then decreased. In addition, the protein expression of TAG1 and APP was consistent with the RT-PCR results. Compared with undifferentiated glioma stem cells, the expression of TAG1 and APP decreased gradually with the extension of differentiation time. In conclusion, the expression of TAG1/APP signaling pathway in glioma cells was abnormal. Thus, this pathway is involved in the proliferation and differentiation of glioma cells and promotes the proliferation of glioma cells to inhibit the differentiation of glioma cells.
\end{abstract}

\section{Introduction}

Glioma has been confirmed as a lethal malignant tumor due to high mortalities caused by gliomas in recent years (1). Modrek et al showed that gliomas account for $29 \%$ of primary

Correspondence to: Dr Shi-Guang Zhao, The First Affiliated Hospital of Harbin Medical University, 23 Youzheng Street, Harbin, Heilongjiang 150001, P.R. China

E-mail: eqwumw9679@163.com

Key words: transient axonal glycoprotein-1, amyloid precursor protein tumors of system diseases, which constitutes $80 \%$ of malignant tumors (2). The incidence of gliomas is approximately $52,400 / 100,000$ individuals (3). Previous findings have shown that approximately $0.602 \%$ of Chinese individuals exhibit varying degrees of increased primary system diseases; thus, there is a high incidence of patients with gliomas in China $(4,5)$. Gliomas are caused by the interaction between human genetic material and the external environment; however, the related genes causing brain glioma have yet to be identified. Therefore, glioma pathogenesis remains to be determined (6).

In recent years, advances in the research on glial stem cells, and the study of the pathogenesis of brain tumors by glial stem cells, have become imperative in the study of gliomas. Robinson et al showed that transient axonal glycoprotein-1 (TAG1) is important in the development of the central nervous system in the human body (7). Previous findings showed that the physiological function of TAG1 is mainly expressed in the human body as a cell adhesion molecule to guide the nerve cells in the adhesion, migration, and increase of axon growth (8). Huang et al found a correlation between TAG1 and glioma (9). Previous results have also shown that amyloid $\beta$ precursor protein (APP) is an important, widely distributed protein in brain, and plays important roles in the promotion of nerve growth, regulation of neuronal migration and differentiation (10). In the present study, we investigated the role of the expression of TAG1/APP signaling pathway in the proliferation and differentiation of glioma stem cells to provide a reference for the study of the genetic mechanism and treatment of brain glioma.

\section{Materials and methods}

Chemicals, cell lines and reagents. In this study, U373 glioma cell lines with hepatocellular function were purchased from the American Type Culture Collection (Manassas, VA, USA). The main components of the serum-free medium included DMEM/F12 + Bfgf $20 \mathrm{ng} / \mathrm{ml}$, EGF $20 \mathrm{ng} / \mathrm{ml}$, and B27 0.2\%. Cells were cultured at $37^{\circ} \mathrm{C}$ with $5 \% \mathrm{CO}_{2}$. Differentiation medium comprised DMEM/F12 culture medium containing $10 \%$ fetal bovine serum, and cells were cultured at $37^{\circ} \mathrm{C}$ with $5 \% \mathrm{CO}_{2}$. The TAG1/APP primary antibodies were purchased from Roche (Mannheim, Germany).

RT-PCR and RNA extraction. RNA extraction was operated in accordance with AXYGEN kit instructions (10). Briefly, 
$500 \mathrm{ng}$ RNA was collected and added to $2.0 \mathrm{ml} 5 \mathrm{X}$ g DNA eraser Buffer, $1.0 \mu \mathrm{g}$ DNA eraser, and RNase-free $\mathrm{ddH}_{2} \mathrm{O}$ to supplement the whole system to $10 \mathrm{ml}$ and the DNA was eliminated from RNA, followed by the addition of $5 \mathrm{ml}$ of the above reaction liquid, $0.5 \mathrm{ml}$ PrimeScript RT Enzyme mix, $2.0 \mathrm{ml}$ 5X Prime Script Buffer and $2.0 \mathrm{ml}$ RT Primer mix. RNase-free $\mathrm{ddH}_{2} \mathrm{O}$ was added to supplement the whole system to $10.0 \mathrm{ml}$. Fluorescent quantitative PCR reaction system was as follows: $5.0 \mathrm{ml} \mathrm{SYBR}$ Premix Ex Taq TMII (2X), $0.3 \mathrm{ml}$ PCR forward primer $(10 \mathrm{mmol} / \mathrm{l}), 0.3 \mathrm{ml}$ PCR reverse primer (10 mmol/l), $1.0 \mathrm{ml} \mathrm{cDNA}$, and $\mathrm{H}_{2} \mathrm{O}$ to supplement the whole system to $20 \mathrm{ml}$. The system was detected as previously described (11).

Fluorescent quantitative PCR. The fluorescence quantitative PCR kit used in the present study was purchased from Takara Biotechnology Co., Ltd. (Dalian, China). The experiment was carried out in triplicate. Specific steps were conducted with reference to the specification, resulting in disease amelioration (Table I).

Western blot analysis. Roche's animal cell protein extraction kit was used to extract the total protein in the sample (specific operation according to the specification) and the operation was optimized (12). Rabbit monoclonal TAG1 antibody (dilution, 1:500; cat. no. ab133498) and rabbit monoclonal APP antibody (dilution, 1:500; cat. no. ab180140) were purchased from Abcam (Cambridge, MA, USA).

ELISA detection. The double antibody sandwich method was used to detect the expression of TAG1/APP gene as previously described (11). Briefly, pH 9.0 PBS buffer was used to dilute the antibody protein, at a concentration of approximately $1-10 \mu \mathrm{g} / \mathrm{ml}$. Then, $0.1 \mathrm{ml}$ of the sample was added in the 96-well plate and the sample was treated at $4^{\circ} \mathrm{C}$ overnight. The following day, the liquid in the well was discarded and the plate was washed with PBS five times for $2 \mathrm{~min}$. Subsequently, $0.1 \mathrm{ml}$ of the treated serum sample was added into the 96-well plate and incubated at $37^{\circ} \mathrm{C}$ for $1 \mathrm{~h}$. The plate was washed five times with PBS for 2 min. Of note, the blank well was used for the negative and positive controls. After washing, $0.1 \mathrm{ml}$ of the secondary antibody was added to the 96-well plate and incubated at $37^{\circ} \mathrm{C}$ for $0.5-1.2 \mathrm{~h}$. After staining with red, the plate was washed five times with PBS for 2 min. After washing, $0.1 \mathrm{ml}$ new configured chromogenic substrate, TMB, was added to the 96 -well plate and incubated at $37^{\circ} \mathrm{C}$ for $30 \mathrm{~min}$, followed by the addition of $0.005 \mathrm{ml}$ of $0.2 \mathrm{M}$ sulfuric acid stop solution.

For qualitative detection, the 96-well plate above was placed on blank paper. By reading the color depth, a qualitative observation was conducted, i.e., a deeper color indicated a higher positive degree, suggesting higher TAG1/APP protein content. The negative control hole was colorless. The 96 -well plate was arranged on the enzyme standard instrument for quantitative detection with $450 \mathrm{~nm}$ as the wavelength. The blank well was adjusted to zero. If the OD value was $>1.2$-fold of the negative control value, a positive state was confirmed (12).

Statistical analysis. SPSS 20.2 statistical software (SPSS, Inc., Chicago, IL, USA) was used for statistical analysis in the
Table I. Fluorescence quantitative PCR primer.

\begin{tabular}{ll}
\hline Gene & \multicolumn{1}{c}{ Primer sequence } \\
\hline TAG1 & F: 5'-AGTCACACCTGTCCTCTAG-3' \\
& R: 5'-ATCTGCCTATGCCTTGGTTG-3' \\
APP & F: 5'-GTGGCTGAGGAGATTCAAG-3' \\
& R: 5'-AAAGAAGGCATGAGAGCATC-3' \\
GAPDH & F: 5'-TCATGGGTGTGAACCATGAGAA-3' \\
& R: 5'-GGCAGGACTGTGGTCATGAG-3' \\
\hline
\end{tabular}

experiment. Measurement data were presented as mean \pm standard deviation. Countable data were tested using the Chi-square test. $\mathrm{P}<0.05$ was considered statistically significant.

\section{Results}

Gene expression of TAGI/APP signaling pathway in glioma stem cell proliferation. To explore the gene expression of TAG1/APP signaling pathway in glioma stem cell proliferation, ordinary glioma and glioma stem cells were collected to extract the RNA. TAG1/APP gene expression status was detected (Fig. 1). The expression of TAG1/APP increased significantly in glioma stem cells. Differences were of statistical significance $(\mathrm{t} 1=-3.427, \mathrm{P}=0.018 ; \mathrm{t} 2=-4.201, \mathrm{P}=0.032)$.

Protein expression of TAGl/APP signaling pathway in glioma stem cell proliferation. The protein expression levels of TAG1/APP protein were studied using ELISA and western blotting, and the results are shown in Fig. 2. The expression of protein of TAG1/APP in glioma stem cells was significantly higher in comparison to the ordinary cells $(\mathrm{t} 3=-3.49, \mathrm{P}=0.021$; $\mathrm{t} 4=-9,782, \mathrm{P}=0.012$ ).

Gene expression of TAG1/APP in the differentiation of glioma stem cells. To further examine the gene expression of TAG1/APP signaling pathway and the differentiation of glioma stem cells, the protein of ordinary glioma and glioma stem cells cultured in differentiation medium was extracted. RNA expression levels of TAG1/APP were determined by RT-PCR. The results revealed a significant increase in the RNA expression levels of TAG1/APP in glioma stem cells $(\mathrm{P} 1=0.003$, $\mathrm{P} 2=0.004)$ (Fig. 3).

Protein expression of TAG1/APP signaling pathway in the differentiation of glioma stem cells. The protein expression of TAG1/APP signaling pathway in glioma stem cell differentiation was examined following protein extraction in ordinary glioma and glioma stem cells cultured in differentiation medium, using ELISA and western blotting. The results shown in Fig. 4 suggest that, the protein expression of TAG1/APP was significantly higher in glioma stem cells $(\mathrm{P} 1=0.002, \mathrm{P} 2=0.001)$.

\section{Discussion}

The recent increase in the incidence of cerebral gliomas results in the deepening of the research on brain glioma (13). 
A
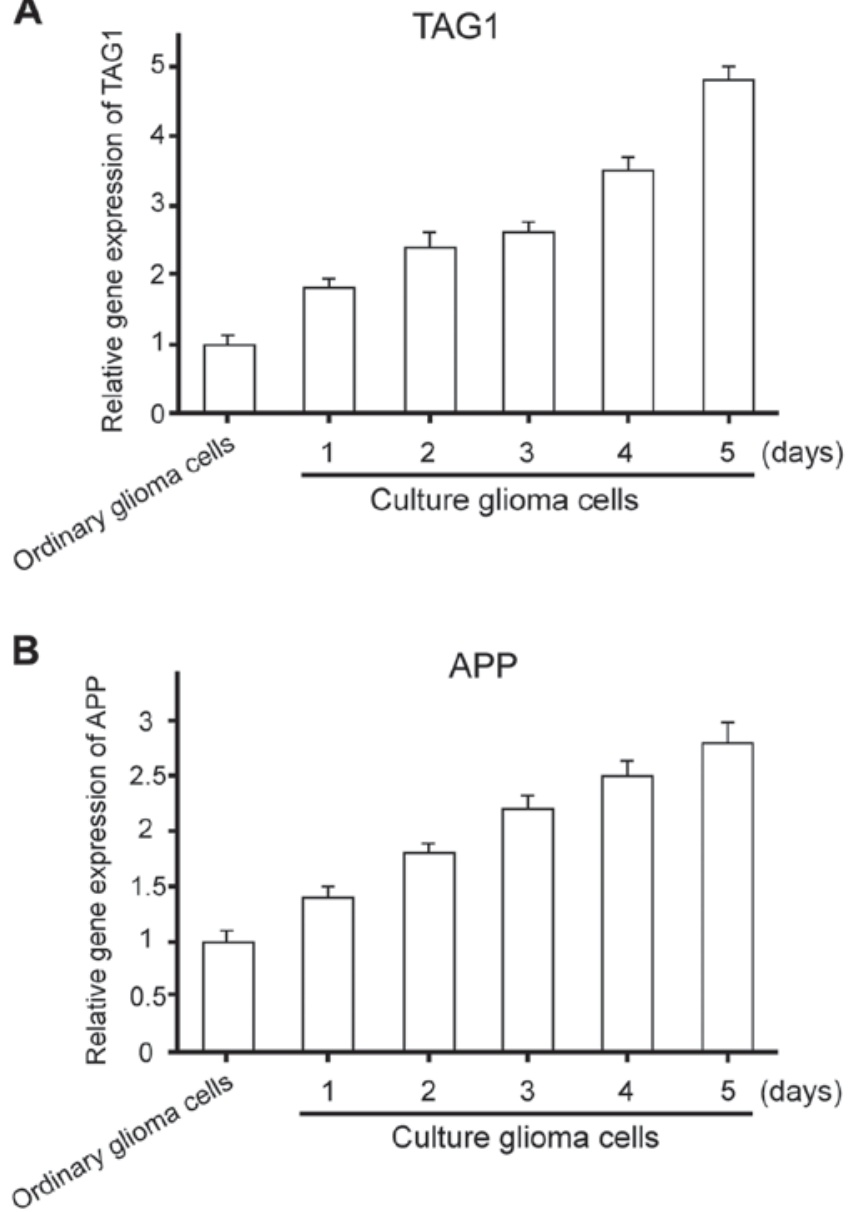

Figure 1. Gene expression of TAG1/APP signaling pathway and glioma stem cell proliferation.

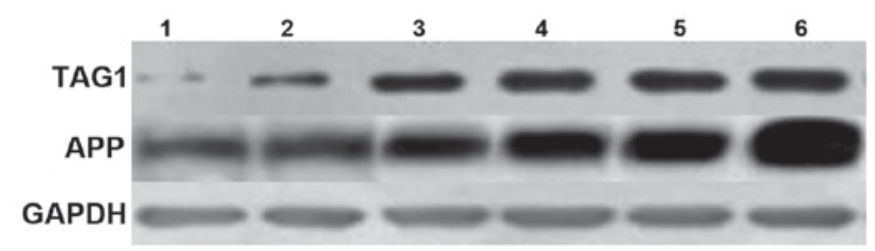

Figure 2. Protein expression of TAG1/APP signaling pathway and the glioma stem cell proliferation.

Researchers are focused on important genes, which are able to affect gliomas such as TAG1 and APP. However, research on the relevant signaling pathway in glioma is rarely reported (14). The present study has focused on this aspect of glioma research and has explored the expression profiles of TAG1/APP signaling pathway in the proliferation and differentiation of glioma stem cells. TAG1 gene is crucial in the signal pathway and can promote axonal formation and remodeling (15). Furthermore, the interaction of TAG1 with glial cells plays an important role in the regulation of glial cell migration (16). We observed a significant increase in the expression profiles of TAG1 in the present study and the results are consistent with an earlier study by Liu et al (17).

The APP protein is another important factor that has signal transfer function $(18,19)$. Results by Nagai et al $(20)$
A

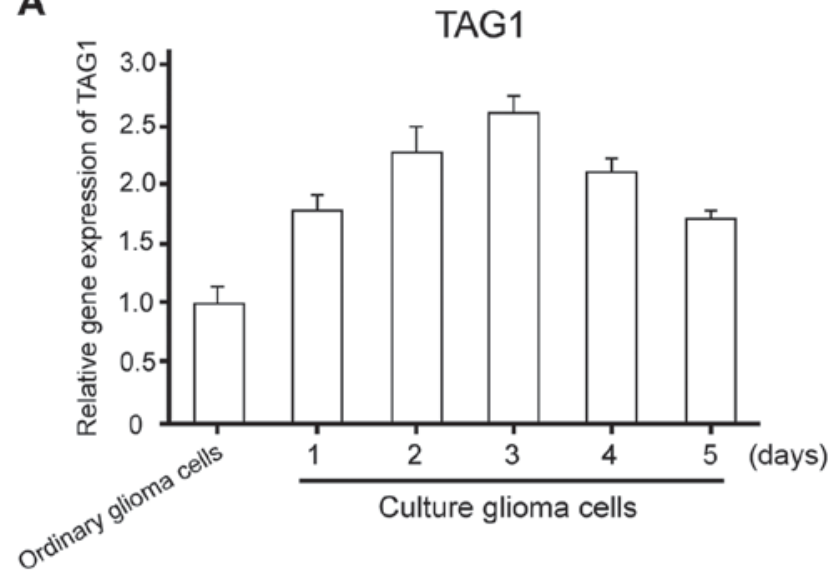

B

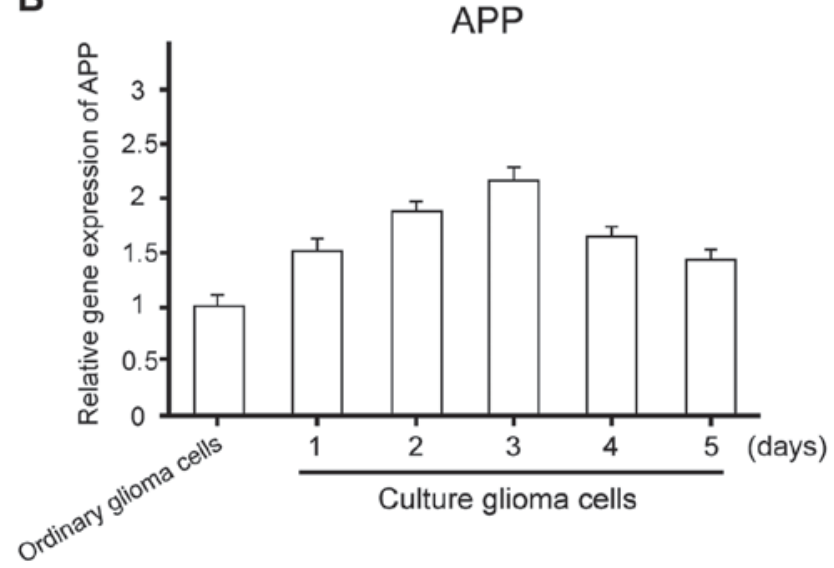

Figure 3. Gene expression of TAG1/APP in the differentiation of glioma stem cells.

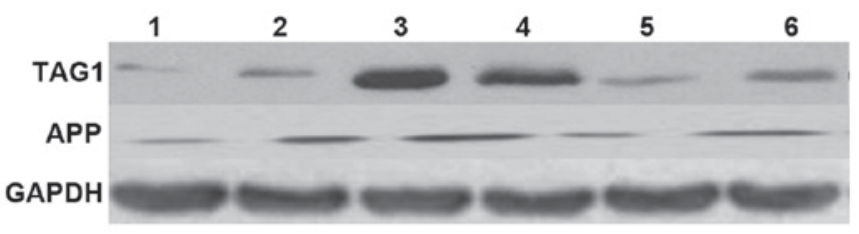

Figure 4. Expression of TAG1/APP protein in the signal and differentiation of glioma stem cells.

showed that the APP gene is also involved in brain and nervous system development and maturation. Chen et al suggested the association of this gene with many types of gliomas (21). We also observed a significant increase in its expression profiles, as observed by Mirzayans et al (22). Therefore, it can be inferred from the abovementioned studies and results that TAG1/APP gene may be involved in the development and maturation of the nervous system, to a certain extent. At present, there are few reports about the expression of TAG1/APP signal pathway that is abnormally expressed in glioma cells. In addition, the TAG1/APP signaling pathway involves glioma stem cell proliferation and differentiation, promotes glioma stem cell proliferation, and inhibits glioma differentiation, which provides certain theoretical and experimental basis to the subsequent diagnosis and treatment of glioma. 


\section{References}

1. Liu S, Yin F, Zhang J, Wicha MS, Chang AE, Fan W, Chen L, Fan $\mathrm{M}$ and Li Q: Regulatory roles of miRNA in the human neural stem cell transformation to glioma stem cells. J Cell Biochem 115: 1368-1380, 2014.

2. Modrek AS, Bayin NS and Placantonakis DG: Brain stem cells as the cell of origin in glioma. World J Stem Cells 6: 43-52, 2014

3. Ostrom QT, Gittleman H, Stetson L, Virk SM and BarnholtzSloan JS: Epidemiology of gliomas. Cancer Treat Res 163: 1-14, 2015.

4. Ooi YC, Tran P,Ung N, Thill K, Trang A, Fong BM, Nagasawa DT, Lim $M$ and Yang I: The role of regulatory T-cells in glioma immunology. Clin Neurol Neurosurg 119: 125-132, 2014.

5. Wang G, Xu S, Cao C, Dong J, Chu Y, He G and Xu Z: Evidence from a large-scale meta-analysis indicates eczema reduces the incidence of glioma. Oncotarget 7: 62598-62606, 2016.

6. Trazzi S, Fuchs C, Valli E, Perini G, Bartesaghi R and Ciani E: The amyloid precursor protein (APP) triplicated gene impairs neuronal precursor differentiation and neurite development through two different domains in the Ts65Dn mouse model for Down syndrome. J Biol Chem 288: 20817-20829, 2013.

7. Robinson A, Grösgen S, Mett J, Zimmer VC, Haupenthal VJ, Hundsdörfer B, Stahlmann CP, Slobodskoy Y, Müller UC, Hartmann T, et al: Upregulation of PGC-1 $\alpha$ expression by Alzheimer's disease-associated pathway: Presenilin 1/amyloid precursor protein (APP)/intracellular domain of APP. Aging Cell 13: 263-272, 2014.

8. Binello E, Mormone E, Emdad L, Kothari H and Germano IM: Characterization of fenofibrate-mediated anti-proliferative pro-apoptotic effects on high-grade gliomas and anti-invasive effects on glioma stem cells. J Neurooncol 117: 225-234, 2014.

9. Huang Q, Zhang QB, Dong J, Wu YY, Shen YT, Zhao YD, Zhu YD, Diao Y, Wang AD and Lan Q: Glioma stem cells are more aggressive in recurrent tumors with malignant progression than in the primary tumor, and both can be maintained long-term in vitro. BMC Cancer 8: 304, 2008.

10. Chen M, Zhang H, Wu J, Xu L, Xu D, Sun J,He Y, Zhou X, Wang Z, $\mathrm{Wu} \mathrm{L}$, et al: Promotion of the induction of cell pluripotency through metabolic remodeling by thyroid hormone triiodothyronine-activated PI3K/AKT signal pathway. Biomaterials 33: 5514-5523, 2012.

11. Ji X, Qiang H and Qing L: Morphological, marker and cell proliferation kinetics of brain tumor stem cells differentiation in vitro. Chin Med J (Engl) 86: 1604-1609, 2006.

12. Sharp J, Frame J, Siegenthaler M, Nistor G and Keirstead HS: Human embryonic stem cell-derived oligodendrocyte progenitor cell transplants improve recovery after cervical spinal cord injury. Stem Cells 28: 152-163, 2010.
13. Macas J, Ku MC, Nern C, Xu Y, Bühler H, Remke M, Synowitz M, Franz K, Seifert V, Plate KH, et al: Generation of neuronal progenitor cells in response to tumors in the human brain. Stem Cells 32: 244-257, 2014

14. Qi R, Li Y, An H, Yu Y, Yang X and Cao X: The effect of Notch1 gene transfection on the growth of Hep3B hepatocarcinoma cells and the related mechanisms. Chin J of Cancer Biother 10: 180-184, 2003 (In Chinese)

15. Clement V, Sanchez P, de Tribolet N, Radovanovic I and Ruiz i Altaba A: HEDGEHOG-GLI1 signaling regulates human glioma growth, cancer stem cell self-renewal, and tumorigenicity. Curr Biol 17: 165-172, 2007.

16. Shang L, Li W and Chen $\mathrm{H}$ : Breeding of the resistant strain of the Bacillus pneumoniae and the construction of the mutant strain of the signal label. J Microbiol 48: 73-79, 2007.

17. Liu ZJ, Xiao M, Balint K, Smalley KS, Brafford P, Qiu R, Pinnix CC, Li X and Herlyn M: Notch1 signaling promotes primary melanoma progression by activating mitogen-activated protein kinase/phosphatidylinositol 3-kinase-Akt pathways and up-regulating N-cadherin expression. Cancer Res 66: 4182-4190, 2006.

18. Esteban MA, Wang T, Qin B, Yang J, Qin D, Cai J, Li W, Weng Z, Chen J, Ni S, et al: Vitamin C enhances the generation of mouse and human induced pluripotent stem cells. Cell Stem Cell 6: 71-79, 2010.

19. Miyoshi N, Ishii H, Nagano H, Haraguchi N, Dewi DL, Kano Y, Nishikawa S, Tanemura M, Mimori K, Tanaka F, et al: Reprogramming of mouse and human cells to pluripotency using mature microRNAs. Cell Stem Cell 8: 633-638, 2011.

20. Nagai K, Ishii H, Miyoshi N, Hoshino H, Saito T, Sato T, Tomimaru Y, Kobayashi S, Nagano H, Sekimoto M, et al: Longterm culture following ES-like gene-induced reprogramming elicits an aggressive phenotype in mutated cholangiocellular carcinoma cells. Biochem Biophys Res Commun 395: 258-263, 2010.

21. Chen J, Fu X, Wan Y, Wang Z, Jiang D and Shi L: miR-125b inhibitor enhance the chemosensitivity of glioblastoma stem cells to temozolomide by targeting Bak1. Tumour Biol 35: 6293-6302, 2014.

22. Mirzayans R, Andrais B, Scott A and Murray D: New insights into p53 signaling and cancer cell response to DNA damage: Implications for cancer therapy. J Biomed Biotechnol 2012: 170325, 2012. 